\title{
Computational Aerodynamic Analysis of Three-dimensional Ice Shapes on a NACA 23012 Airfoil
}

\author{
GaRam Jun ${ }^{1}$ \\ University of Michigan, Ann Arbor, MI, 48109, USA \\ Daniel Oliden ${ }^{2}$ \\ Arizona State University, Tempe, AZ, 85287, USA \\ Mark G. Potapczuk ${ }^{3}$ \\ NASA Glenn Research Center, Cleveland, OH, 44135, USA \\ and \\ Jen-Ching Tsao ${ }^{4}$ \\ Ohio Aerospace Institute, Cleveland, OH, 44142, USA
}

\begin{abstract}
The present study identifies a process for performing computational fluid dynamic calculations of the flow over full three-dimensional (3D) representations of complex ice shapes deposited on aircraft surfaces. Rime and glaze icing geometries formed on a NACA23012 airfoil model were obtained during testing in the NASA Glenn Research Center's Icing Research Tunnel (IRT). The ice shape geometries were scanned as a cloud of data points using a 3D laser scanner. The data point clouds were meshed using Geomagic software to create highly accurate models of the ice surface. The surface data was imported into Pointwise grid generation software to create the CFD surface and volume grids. It was determined that generating grids in Pointwise for complex 3D icing geometries was possible using various techniques that depended on the ice shape. Computations of the flow fields over these ice shapes were performed using the NASA National Combustion Code (NCC). Results for a rime ice shape for angle of attack conditions ranging from 0 to 10 degrees and for freestream Mach numbers of 0.10 and 0.18 are presented. For validation of the computational results, comparisons were made to test results from rapid-prototype models of the selected ice accretion shapes, obtained from a separate study in a subsonic wind tunnel at the University of Illinois at Urbana-Champaign. The computational and experimental results were compared for values of pressure coefficient and lift. Initial results show fairly good agreement for rime ice accretion simulations across the range of conditions examined. The glaze ice results are promising but require some further examination.
\end{abstract}

\section{Nomenclature}

$\begin{array}{ll}\text { AOA } & =\text { Angle of Attack } \\ \text { CFD } & =\text { Computational Fluid Dynamics } \\ \text { NCC } & =\text { National Combustion Code } \\ C_{f} & =\text { skin friction } \\ R e_{s} & =\text { Reynolds number based on distance along the surface } \\ U_{\infty} & =\text { free stream velocity } \\ u_{*} & =\text { friction velocity }\end{array}$

\footnotetext{
${ }^{1}$ Graduate Student, Department of Aerospace Engineering, 530 S. State St.

${ }^{2}$ Graduate Student, Department of Aerospace Engineering, University Drive and Mill Avenue.

${ }^{3}$ Research Aerospace Engineer, Icing Branch, 21000 Brookpark Rd., MS 11-2, Senior Member.

${ }^{4}$ Principal Research Scientist, Icing Branch, 21000 Brookpark Rd., MS 11-2, AIAA Associate Fellow
} 


$\begin{array}{ll}y & =\text { distance above the local surface } \\ y^{+} & =\text {non-dimensional wall distance for a wall-bounded flow } \\ \tau_{w} & =\text { wall shear stress } \\ \rho & =\text { density of air }\end{array}$

\section{Introduction}

Icing continues to be a major safety concern for the aircraft industry. Previous studies ${ }^{1,2}$ have shown that aerodynamic performance significantly degrades as ice accretes onto the wings. Depending on the ice shape geometry, there can be a substantial change in performance characteristics such as lift, drag, and pitching moment. Icing decreases the stall angle of attack, affecting the maximum coefficient of lift, while drastically increasing the drag of the wing which can lead to catastrophic results if the pilot is unaware of such effects. Therefore, icing research has been conducted extensively throughout the past several decades.

Understanding the impact on the aerodynamic performance of aircraft wings resulting from changes to the surface geometry during in-flight ice deposition continues to be a topic of interest from the perspective of experimental and computational investigations. Although numerous experimental studies have been performed to obtain aerodynamic data for full 3D ice shape geometries ${ }^{2,3,4}$, computational studies to date have been limited to 2D cross-sections $^{5,6}$, 3D extrusions of two dimensional cross-sections ${ }^{7,8}$, and smooth 3D ice shapes generated by ice accretion codes. ${ }^{9}$ The ability to calculate the flow over a more accurate representation of an actual ice accretion surface has the potential to provide more information for determination of how ice shapes alter wing aerodynamics and how ice shape roughness impacts convective heat transfer rates during the accretion process. These improvements in turn could lead to more accurate ice accretion simulation tools and a more robust analysis of the impact of an icing encounter.

Recent improvements in laser scanning technology and the associated post-processing software have enabled the recording of detailed ice shape surface geometry information. That digital representation of a complete ice shape, including surface roughness characteristics, can potentially be used to create rapid-prototype models of ice shapes and may also be used in grid generation software to develop realistic surface grids for use in computational fluid dynamic software. The goal of this study is to investigate the use of such data for the latter purpose in order to develop a methodology for determination of the aerodynamic impact of realistic ice shape geometries. The results of these initial studies indicate that the geometry data can be captured using commercial grid generation tools and that realistic aerodynamic results can be obtained. As this is an initial investigation into the use of the scanner data, a comprehensive examination of the details of the computational results was not performed but rather such an effort should form the basis for future studies.

\section{Methods}

In order to computationally analyze the 3D ice shape geometries, detailed surface grids representing the ice shape geometry need to be generated. In a separate study conducted in the Icing Research Tunnel (IRT) at NASA Glenn Research Center, a 3D laser scanner was used to collect a cloud of data points that correspond to surface locations for highly detailed 3D geometries of rime and glaze ice shapes. Lee, et al. ${ }^{10}$ provides a description of the process used to scan the data. Photographs of the actual ice shapes used in this study are shown in Figure 1.

Once the cloud of data points has been acquired, the Geomagic ${ }^{11}$ software package was used to generate representations of the surface suitable for use in grid generation software. Using Geomagic, the data points were connected in a grid-like manner to create polygonal cells representing the ice surface that captured the overall structure and the small-scale roughness features of the ice accretion. Due to the line-of-sight nature of the 3D scanning method, small patches with no data points were often found around highly concave geometric features. Interpolation is needed at these locations and was accomplished using features found within Geomagic. The end result of this post-processing effort is a water-tight surface representation of the scanned ice shape. Results of the scanning and post-processing with Geomagic are shown in Figure 2.

Taking the surface models generated from Geomagic, CFD surface and volume grids were generated around the ice accreted airfoil models. Pointwise ${ }^{12}$, a CFD grid generation software package, was used to generate the CFD grids for the icing geometry models. The output of the Geomagic software can be imported into Pointwise as either a database surface or as a surface grid. If it is imported as a database, the surface grid is constructed from that database information. If the geometry is imported as a grid, then the surface grid generation step can be skipped and the volume grid can be generated. This is only recommended if the geometry is very complex and grid domains cannot 


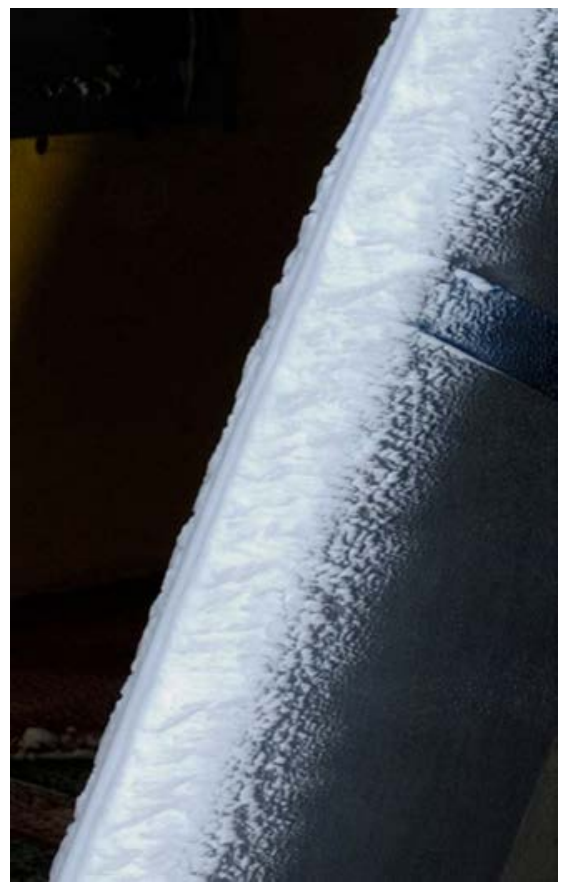

a) Rime Ice Accretion

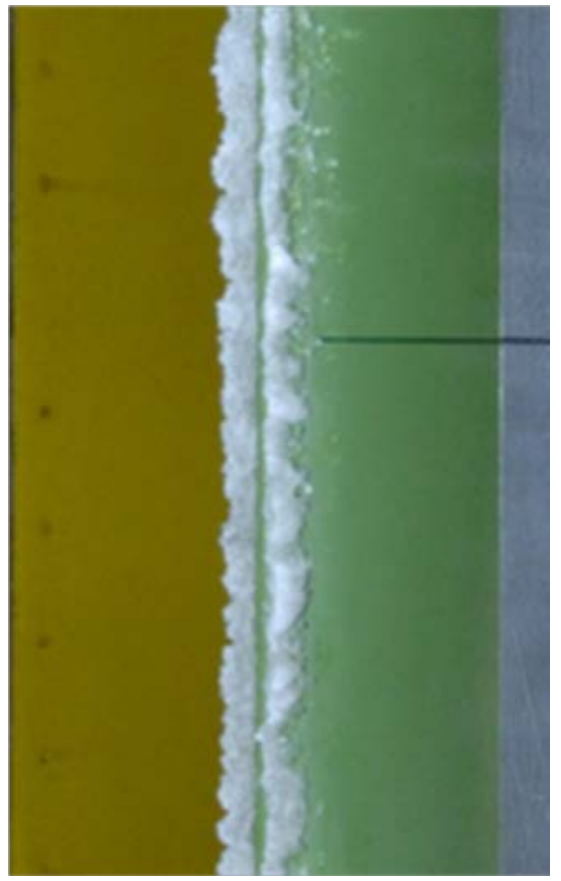

b) Glaze Ice Accretion

Figure 1. Rime and Glaze Ice Accretions on a NACA 23012 Airfoil Model

be created around the geometry from the database format, such as the glaze ice accretion shown below. (Domains are the terminology used in the Pointwise software to identify surfaces and other boundaries of volumes created by the user in the process of making the overall grid structure.) Importing the geometry directly as a grid prevents the user from changing the number of cells on the grid, making refinement or smoothing impossible. During this study, the rime ice shapes were imported as databases while the glaze ice shapes were imported as grids. Importing the grid for the latter case was done because it was found that importing the more complex glaze shape as a database led to problems in accurately projecting the domains onto the surface, which in turn made creation of a block

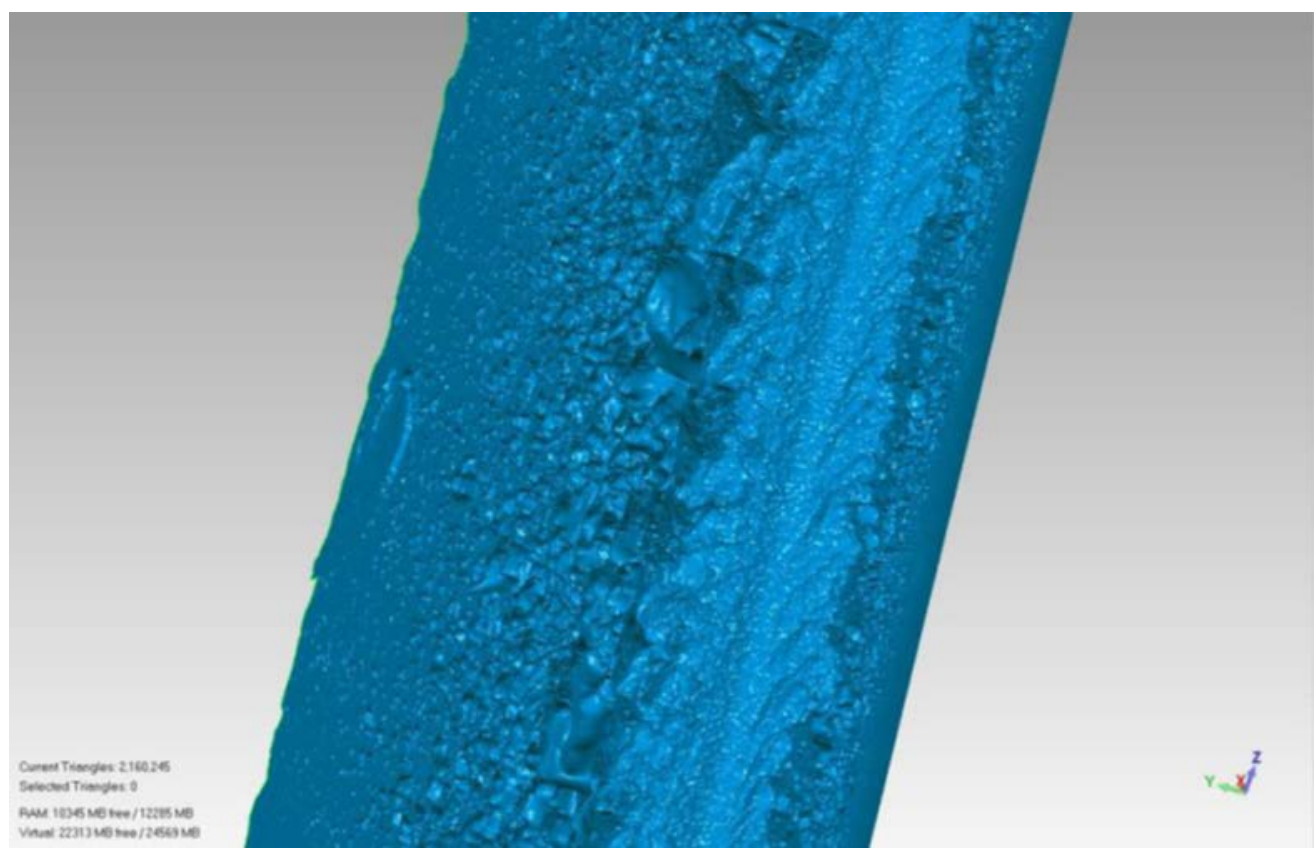

Figure 2. Scanned Ice Shape from NACA 23012 Airfoil Model. 
(a subset of the overall volume grid) problematic. The surface grid representation of the roughness for the rime ice shape could be changed within the Pointwise software but similar modifications for the glaze ice shapes had to be modified using Geomagic and then re-imported into Pointwise. A surface grid is shown in Figure 3 for the rime ice accretion and a surface and volume grid is shown for the glaze ice accretion in Figure 4.

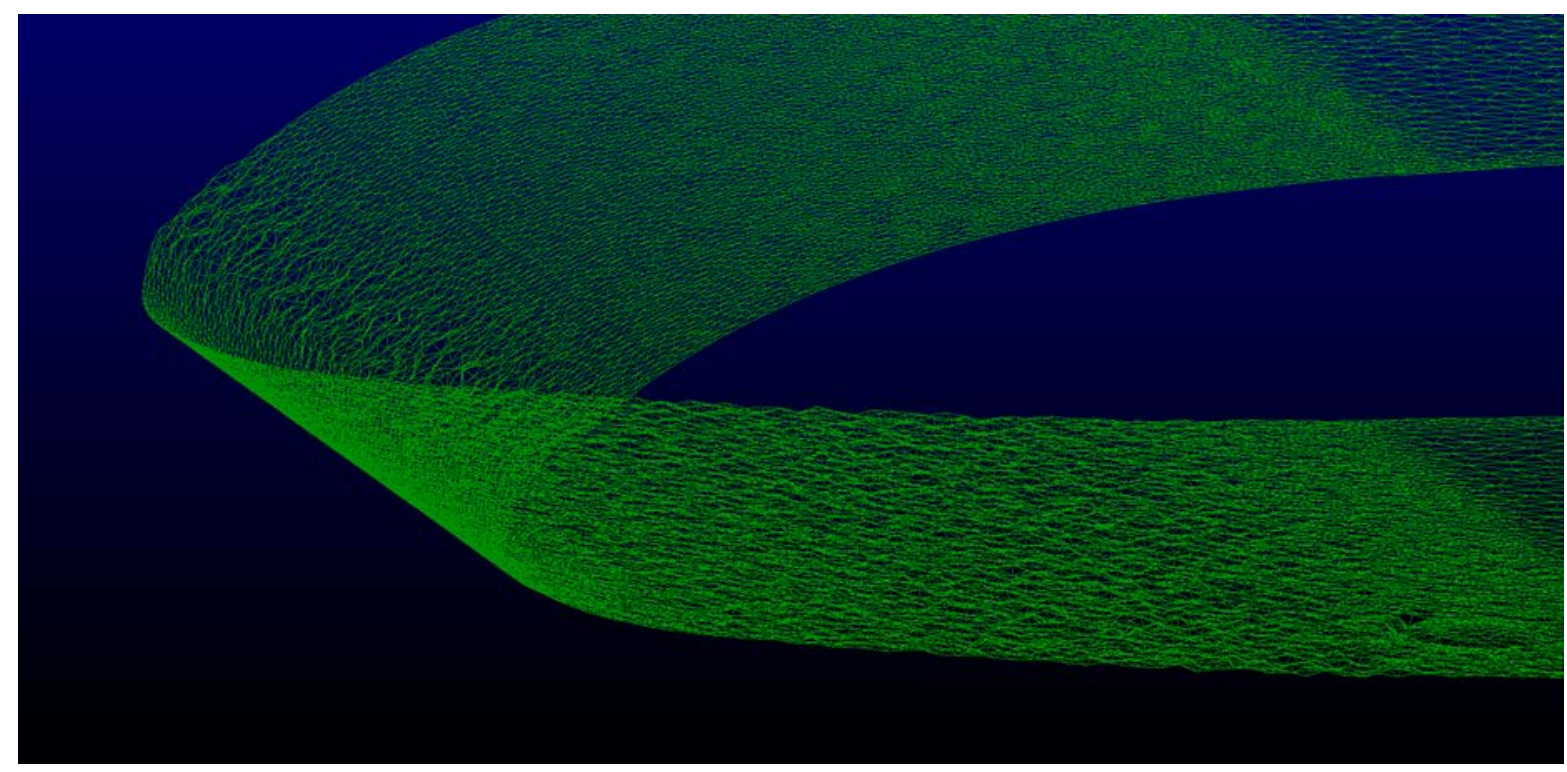

Figure 3. Surface Mesh for Rime Ice Accretion.

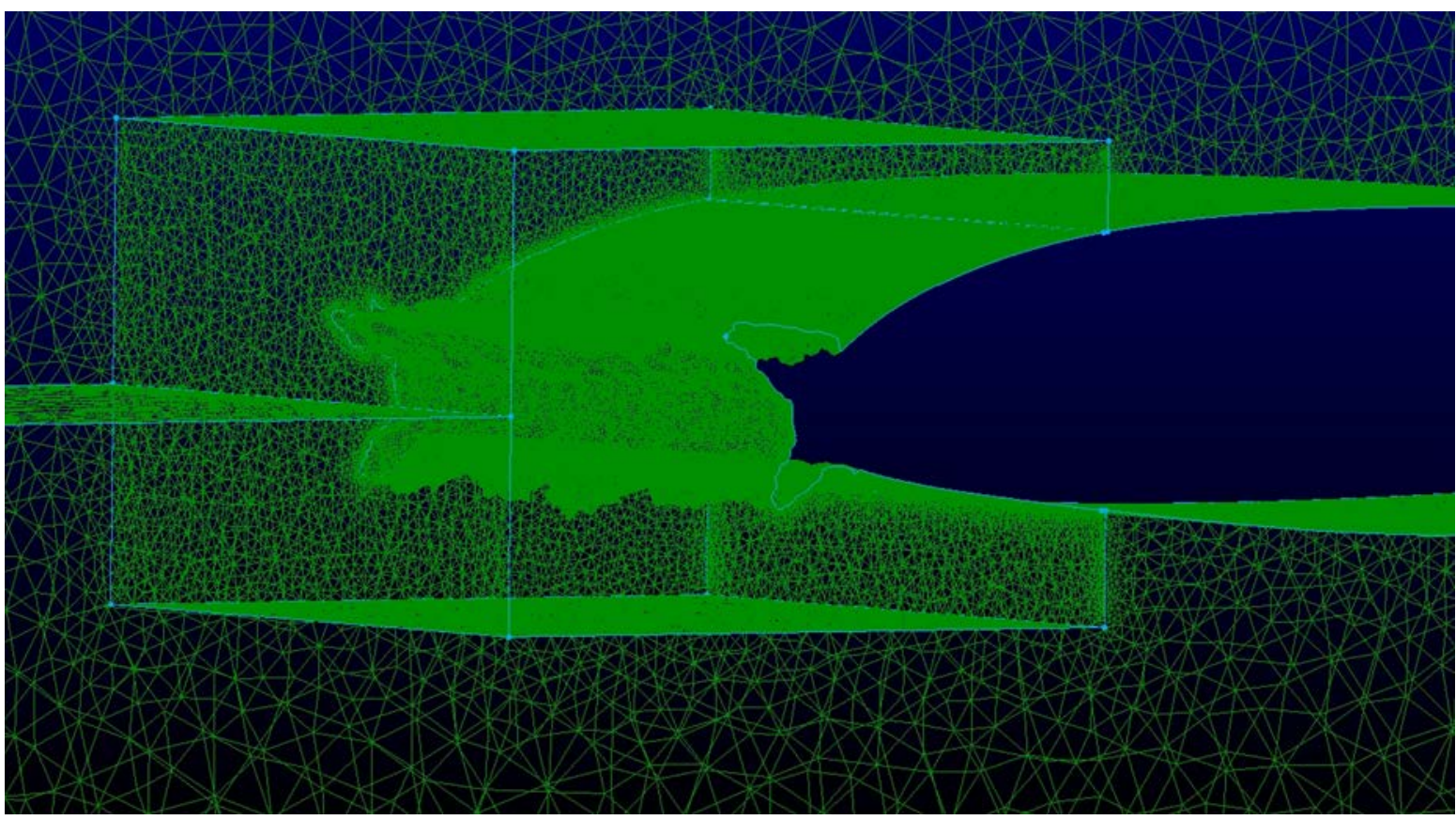

Figure 4. Surface and Volume Mesh for a Glaze Ice Accretion.

When creating any surface or volume grid, the user can choose to build the grid as a structured or unstructured grid. Structured grids enable faster computation times because each node is tabulated in a way such that every adjacent node is known. This tabulation allows the CFD solver to quickly solve the flow field within each cell because the solver can easily access the information in adjacent cells. Structured grids, however, are more difficult to manipulate to fully capture complex geometries such as ice shapes. The generation of a structured grid on the rime ice shape was attempted but in order to accurately capture the geometry, the overall grid had more than 200 million cells which was considered excessive. Therefore, for this study, an unstructured grid was used for the ice 
accretion surfaces. An unstructured grid is good for capturing a lot of the detail in a complex geometry but requires more computation time per node, as the node locations are not stored with respect to adjacent nodes. Figures 3 and 4 provide examples of the unstructured grids used for this study.

Grid refinement is an important part of the grid generation process as it directly affects the accuracy of the flow solution. Refinement and concentrating cells in regions of aerodynamic importance is absolutely necessary to fully capture flow features such as boundary layer growth, vortex shedding, trailing edge wake, and flow separation. This may require refinement of the grid after initial calculations have been performed to understand where refinements are needed. Adaptive mesh technology could also be used for such refinement efforts but that was beyond the scope of this study. The amount of refinement needed to fully capture the boundary layer for a viscous flow relies on the $\mathrm{y}^{+}$ value as well as free stream flow parameters. Assuming the Reynolds number, free stream velocity, and density are known, a $\mathrm{y}^{+}$value can be chosen which allows the turbulence model to fully capture the boundary layer. This in turn provides an estimate to the grid spacing normal to a wall surface. The following procedure gives an initial estimate to the wall distance for the first cell above the wing surface. First the skin friction is estimated using the expression from Schlichting shown in Equation (1).

$$
C_{f}=\left[2 \log _{10}\left(R e_{s}\right)-0.65\right]^{-2.3} \text { for } R e_{s}<10^{9}
$$

Then the wall shear stress is computed using Equation (2).

$$
\tau_{w}=C_{f} * \frac{1}{2} \rho U_{\infty}^{2}
$$

Using the wall shear stress, the friction velocity can be calculated using Equation (3).

$$
u_{*}=\sqrt{\frac{\tau_{w}}{\rho}}
$$

Finally, the wall distance of the cell nearest to the surface can be calculated using Equation (4).

$$
y=\frac{y^{+} \mu}{\rho u_{*}}
$$

The y value can then be used as the initial cell size normal to the surface.

In addition to grid spacing at the surface, grid refinement is also needed to make sure that cell skewness is minimized. Highly skewed cells can affect the convergence of the grid and in a worst case scenario they can prevent convergence entirely. Using an O-grid or C-grid for airfoils and wings generally prevents skewed cells, but for these complex geometries skewness needs to be monitored and evaluated near the ice shape where very sharp angles are present. Use of tools available in grid generation software to monitor such grid quality metrics is an important part of the grid development process.

If the volume grid is generated as an unstructured grid, Pointwise offers a unique tool called T-Rex gridding that generates layers of tetrahedral cells which better capture the flow in the boundary layer region. The number of layers, the growth rate of these layers, and the initial cell size in the first layer can all be varied to generate different size tetrahedral layers for different flow conditions. An example of the T-Rex gridding method as applied to the rime ice configuration is shown in Figure 5.

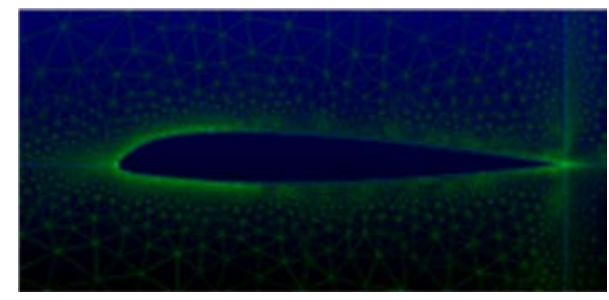

a) Without T-Rex

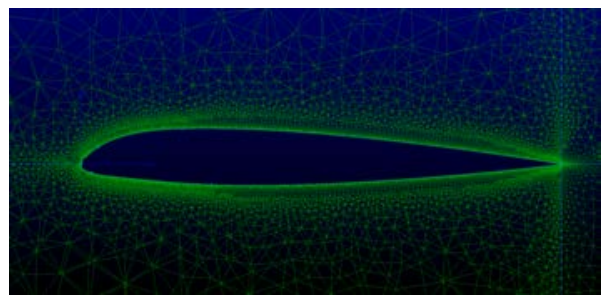

b) With T-Rex

Figure 5. Example of the T-Rex Grid Generation Applied to Rime Ice Configuration. 
A second major goal of this study was to investigate the feasibility of generating CFD grids that would converge to a valid flow solution in a CFD solver. Initially, clean wing simulations were performed for validation of coefficient of pressure, coefficient of lift and coefficient of drag aerodynamic performance properties using the CFD software selected for this study, the National Combustion Code ${ }^{13-15}$ (NCC). Rime and glaze ice accreted wings were then run in NCC for simulation validation with wind tunnel data.

NCC has been and continues to be developed at the NASA Glenn Research Center and is used to perform the steady and unsteady Reynolds-averaged Navier-Stokes (RANS, URANS) simulations for this numerical study. The unstructured formulation of the main solver enables the mixing of various types of 2D and 3D elements for more efficiently modeling the problems of interest. Currently, it accepts quadrilateral and triangular meshes for twodimensional geometries and tetrahedral, prismatic and hexahedral meshes for three-dimensional geometries. The code also takes advantage of modern parallel algorithms so that it can be executed on a wide range of computer platforms. The parallelization is done via automatic domain decomposition that subdivides the entire domain to the number of available processors (or workstations) on the network. The underlying message passing library can be either PVM (Parallel Virtual Machine) or MPI (Message Passing Interface).

The main solver, Corsair-CCD, is a finite-volume code with an explicit, four-stage Runge-Kutta integration algorithm. A time preconditioning technique ${ }^{16}$ is used to enhance the numerical efficiency for low speed flow computation. Local time stepping and residual smoothing are used to accelerate the convergence. A two-equation $(\kappa-\varepsilon)$ turbulence model is used in the solver with the option of either generalized wall function or direct integration as the turbulent wall boundary conditions. Furthermore, in addition to the standard $\kappa-\varepsilon$ model, a higher order nonlinear treatment of the turbulence stress term is included for better prediction of the turbulent flows with possible rotation and swirling ${ }^{17}$, e.g. iced airfoil models and rotor blades in static/dynamic stall or in local ice-induced separated flow.

In recent years, the NCC software team has further developed a turbulence modeling approach ${ }^{18,19}$, called partially resolved numerical simulation (PRNS), that is capable of extracting some of the large-scale unsteady features of turbulent flows at reasonable computational costs. This approach affords an intermediate resolution of turbulence scales relative to those of RANS and LES and has the characteristics of the very large-eddy simulation (VLES). The very large scales of turbulence are directly calculated, and the effects of the unresolved scales are accounted for by an eddy viscosity model that is evolved from state-of-the-art models used in the RANS approach. NCC was developed and is used primarily for the development of combustion technology but its advancements ${ }^{20}$ made in the areas of turbulence modeling, numerical simulation and computing platforms also greatly facilitates the application to 3D iced aerodynamics CFD simulations. This numerical platform has demonstrated its improved capability and flexibility with many benchmark validation cases ${ }^{21}$, modeling complex internal reacting flow and external unsteady flow separation in static stall. These features are the reason for its use in this study.

NCC requires specification of the following boundary conditions; inlet, exit, and side wall. In this study, periodic boundary conditions were used for the side walls. Periodic boundary conditions allow for any span-wise flow that is at one side to be transferred over to the other side which simulates an "infinite" wingspan where there is no wall effect to perturb the flow. This is not quite the situation for an airfoil with ice on the leading edge as the ice shape geometry on one side of the airfoil is not exactly the same as the geometry on the opposite side. Future studies could be conducted to examine the impact of this boundary condition selection for the analysis. For the inlet and exit boundary conditions, free stream conditions such as velocity, pressure, density, and temperature are required. Different values are used to change the effective angle of attack or altitude or Mach number that the geometry will experience. Figure 6 shows all of the prescribed boundary conditions for a C-grid case.

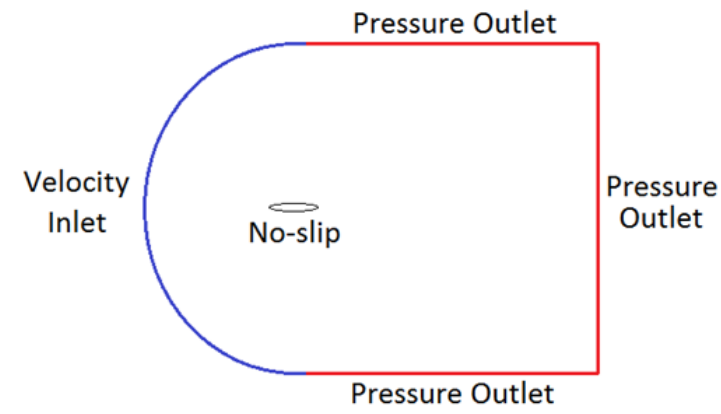

Side View

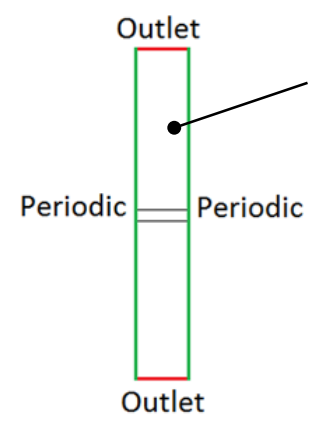

Front View
Velocity Inlet

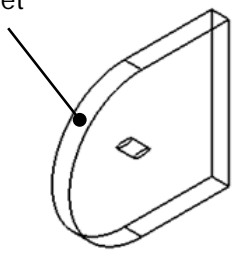

Isometric View

Figure 6. Prescribed Boundary Conditions Used for C-grid in NCC. 
The output from NCC only provides values for local gauge pressure and no other aerodynamic parameter because NCC was designed for analyzing combustors. Therefore, it was necessary to develop an external method of calculating coefficient of pressure, lift, and drag using the local gauge pressure. First the results were imported into Tecplot $360^{22}$, a data viewing software package. There, a macro split up the 3D results into 2D cross-sections and calculated the coefficient of pressure using Equation (5).

$$
C_{p}=\frac{p_{g}}{1 / 2^{2} \rho_{\infty} U_{\infty}^{2}}
$$

Using the coefficient of pressure values along the surface, the area underneath the coefficient of pressure was computed to calculate the normal and tangential force that would be used to calculate the coefficient of lift and drag. A trapezoidal area was assumed as the integration method. This computation was written in Python and performed as a post processing task after the NCC calculation. At the time of this writing, the drag computations for that script were not complete so only lift value comparisons will be presented in the results section.

\section{Results}

Computational results needed to be validated by comparison with experimental results. The ice shape geometry data generated from the scanning process and used to generate the CFD grids were also used to create rapidprototype models which were tested in a subsonic wind tunnel at the University of Illinois at Urbana-Champaign ${ }^{23}$. Pressure measurements as well as lift, drag, and moment measurements were recorded and calculated for an angle of attack sweep at two different test conditions. These test conditions are speeds of Mach 0.10 and 0.18 , with a respective Reynolds numbers of $1.0 \times 10^{6}$ and $1.8 \times 10^{6}$. Static pressure was slightly below atmospheric, at approximately 98,600 Pa with a static temperature of $294 \mathrm{~K}$. A sweep of angle of attack included -9 to 18 degrees during the test program. The same test conditions for the wind tunnel were used when running the CFD simulations using NCC, with the exception that we limited ourselves to 0 to 10 degrees incidence angle.

As mentioned, NCC can be run in steady-state and unsteady modes. The calculations for this study were performed in an unsteady mode due to the nature of the flow near the surface. While the main flow on the scale of the airfoil model chord would be steady-state, it was anticipated that the flow over the ice shapes, especially around roughness elements, would be unsteady. As such, the pressure coefficient and lift results presented herein reflect the instantaneous nature of the flow. This is especially evident in the results for the glaze ice shape described below. Time averaging of the results was not performed during this study but could provide greater agreement with experiment and could form an element of future studies.

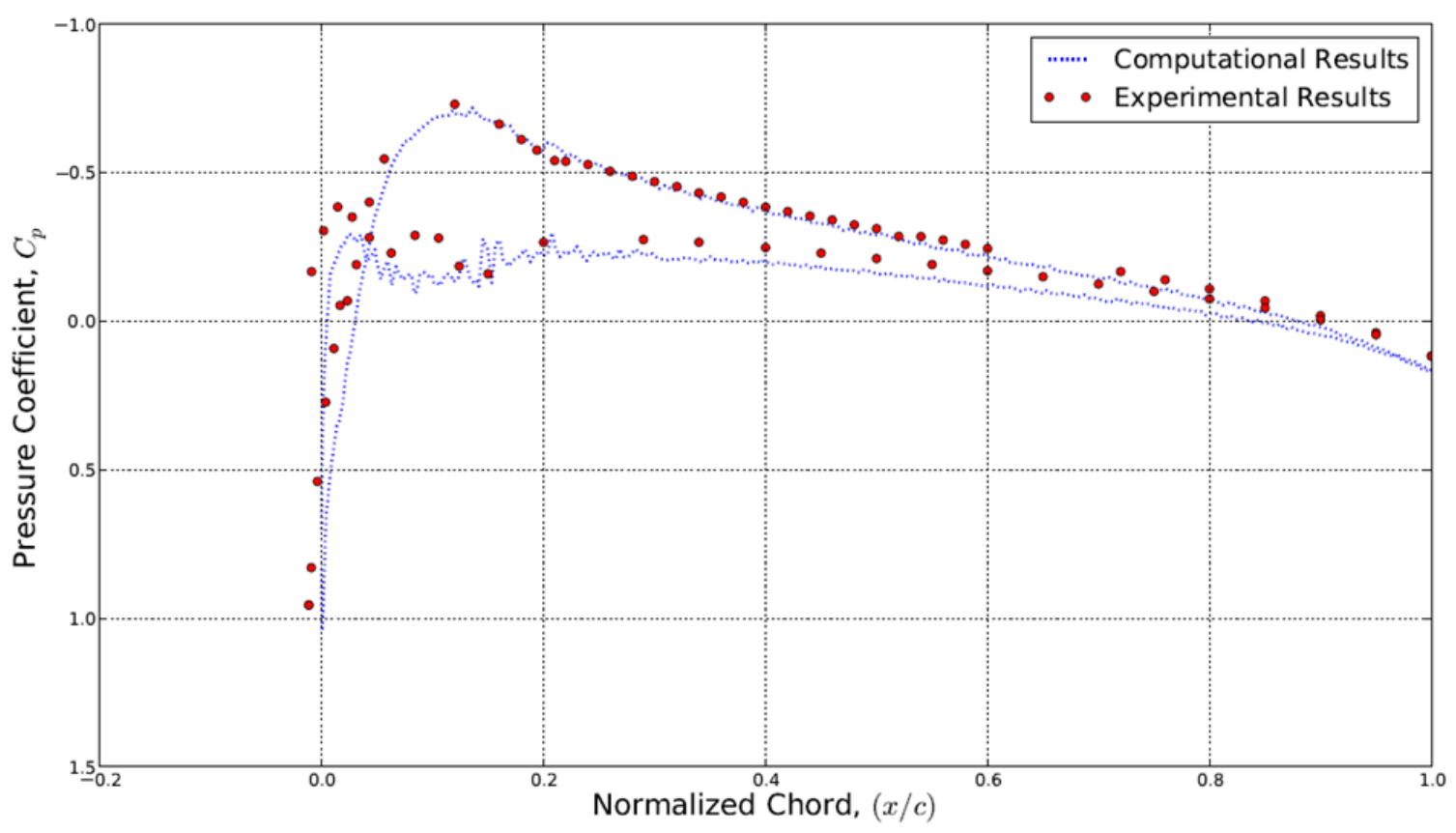

Figure 7. Pressure Coefficient Results for the Rime Ice Geometry, Mid-Span Location. 
Coefficient of pressure at a zero angle of attack for the rime ice accretion case is shown in Figure 7. This coefficient of pressure is taken at a half-span location of the 3D geometry. Preliminary results show fair correspondence between the experimental data and computational results but some anomalies are present. The pressure coefficient curves have a difference between experimental and computational results, specifically on the lower surface of the airfoil. Upper surface pressure correlates very well with a small discrepancy at the trailing edge. Integrating the coefficient of pressure across the upper and lower surface yields a coefficient of lift of 0.1366, resulting in a $15.4 \%$ difference with experimental data.

Pressure contour plots are shown in Figure 8. These plots show the results for a clean (a) and rime ice (b) configuration. The contours show that the rime ice accretion does not substantially disturb the flow over the airfoil model. More detailed evaluations of the flow near the surface will be required to reveal the changes to the air flow resulting from the rime ice shape and its associated roughness features. Such an evaluation is made possible as a result of being able to capture the details of the rime ice surface geometry. That analysis is beyond the scope of the current study.

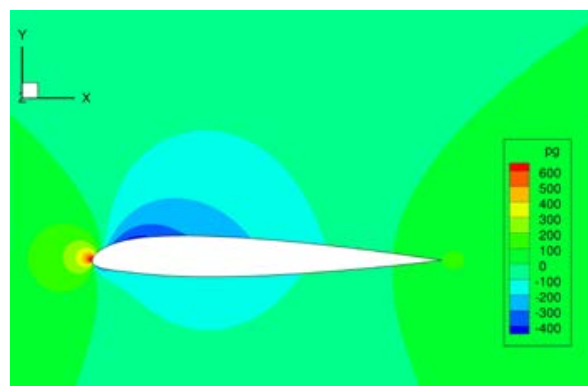

a) clean airfoil model

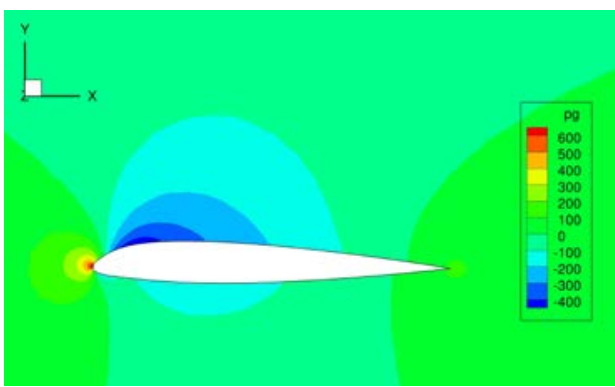

b) airfoil model with rime ice accretion

Figure 8. Gauge Pressure Contour for NACA 23012 Airfoil Model, AOA $=0^{\circ}, \operatorname{Re}=1.0 \times 10^{6}, M=0.1$

Similarly, the coefficient of pressure at zero angle of attack is shown for the glaze ice accretion case. This coefficient of pressure is taken at a half-span location as well. Referring to Figure 9, the pressure coefficient varies largely at the leading edge of the airfoil due to the complex and irregular geometry. These fluctuations may also be a result of the unsteady nature of the flow around the horn region. Further examination, using time averaging of instantaneous results, may be needed to determine if that is the reason for the discrepancy in this region.

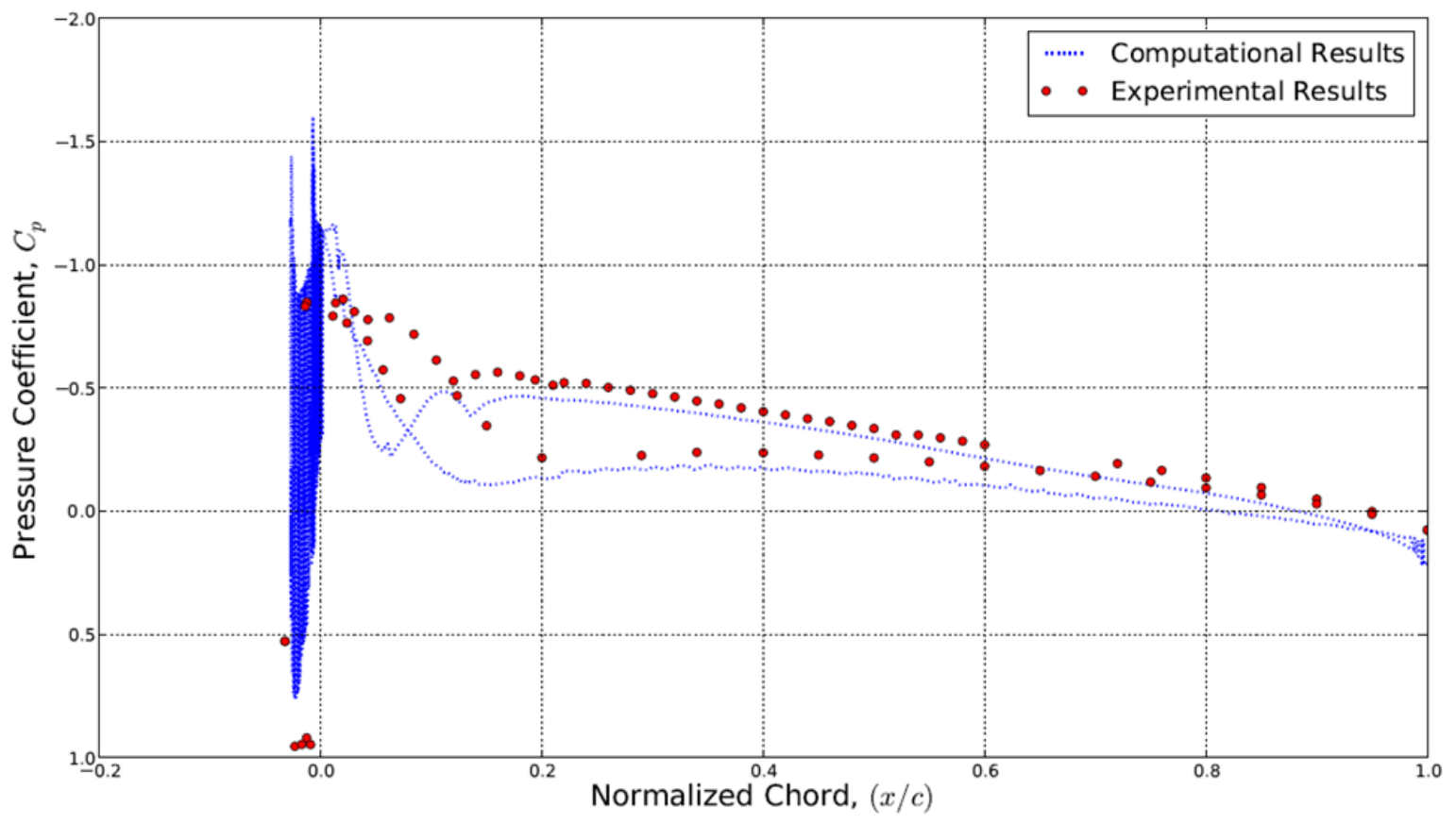

Figure 9. Pressure Coefficient Results for the Glaze Ice Geometry, Mid-Span Location. 
Downstream of the leading edge, it is seen that both computational upper and lower pressure curves are underestimated in comparison to the experimental data. Further examination of this case is required before meaningful results can be discussed. Some features of the computation that should be mentioned are the flow separation that occurs around the horns. Previous studies ${ }^{24}$ have shown that higher grid resolution in the shear layer dividing the separated flow from the main free stream flow results in more realistic results for geometries such as this one. It is anticipated that more work along those lines is needed for this computation. For the purposes of this study it was our intention to determine whether a complete representation of a glaze ice shape could be prepared in commercial grid generation software and if a CFD solution could be obtained.

The glaze ice results indicate that further examination of that geometry is required to understand the differences between computation and experiment. The pressure contour results shown in Figure 10 show a significant change from the pressure contours shown in Figure 8a for a clean NACA 23012 airfoil model. These initial results suggest that the ice shape geometry plays a major role in the outcome and that the surface roughness may be less influential. However, as for the rime ice results, further analysis will be necessary to confirm such observations.

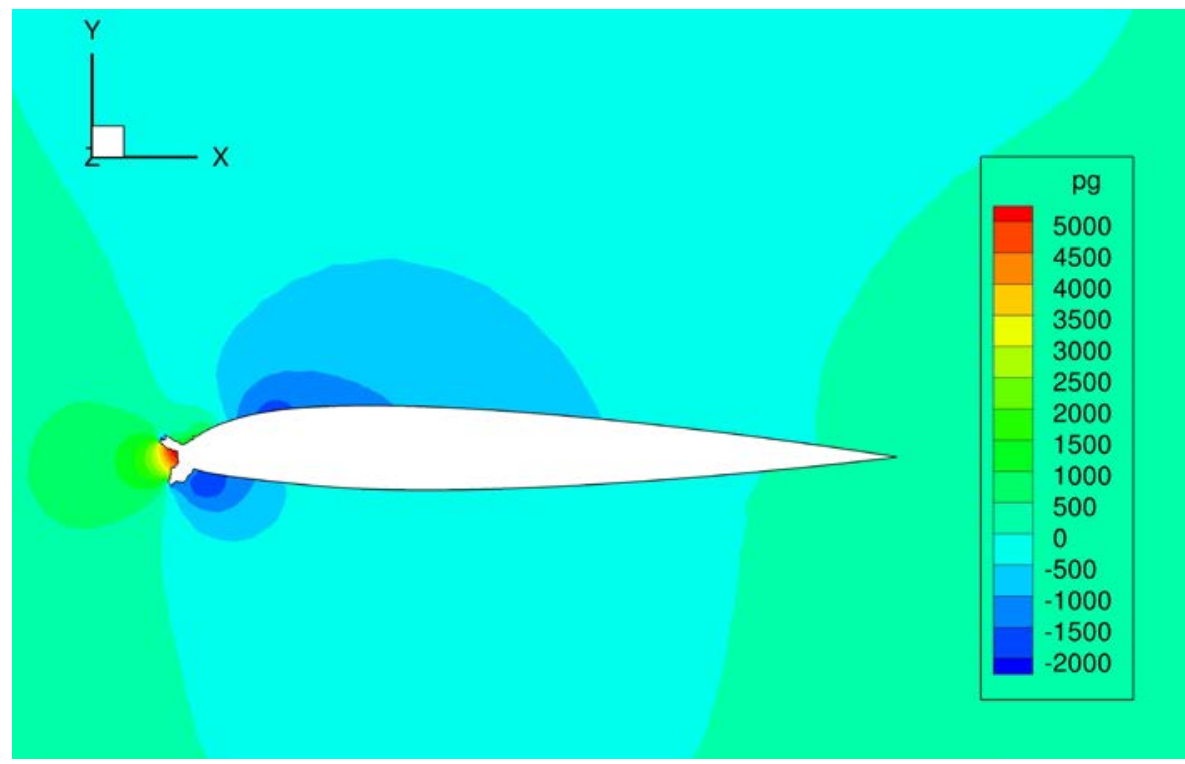

Figure 10. Gauge Pressure Contour for NACA 23012 Airfoil Model with Glaze Ice Accretion,

$$
\mathrm{AOA}=0^{\circ}, \operatorname{Re}=1.0 \times 10^{6}, \mathrm{M}=0.1
$$

Since the rime ice results at zero degrees AOA reasonably matched the experiments, computations at several other angle of attack conditions and at a second Reynolds number, Mach number combination were performed. The results are summarized in the lift versus angle of attack plots shown in Figure 11.

The average percent difference between computation and experiment for the low Re, $\mathrm{M}$ case is $15.2 \%$ with a minimum difference of $6.8 \%$ and a maximum difference of $21.3 \%$. For the higher Re, $\mathrm{M}$ condition, the average difference is $11.5 \%$ with a minimum difference of $8.1 \%$ and a maximum difference of $19.4 \%$. The absolute difference between computation and experiment increases with increasing angle of attack for both the low Re, $\mathrm{M}$ condition as well as the high Re, M condition.

These results indicate two trends. As the angle of attack increases, the difference between the computation and experiment increases. Additionally, as the Reynolds number and Mach number increase the differences between the computation and experiment decrease. With the angle of attack increase the influence of the ice shape on the pressure profile becomes more important. Thus, accurate modeling of the unsteady and locally separated flow becomes more important. The results suggest that further study is required to understand the influence of ice shape measurement resolution and associated surface grid spacing to better understand the requirements for accurate simulation. This also suggests that greater attention to the drag results should be considered in future work as detailed examination of the surface flow features should provide clues on how best to simulate these shapes. 


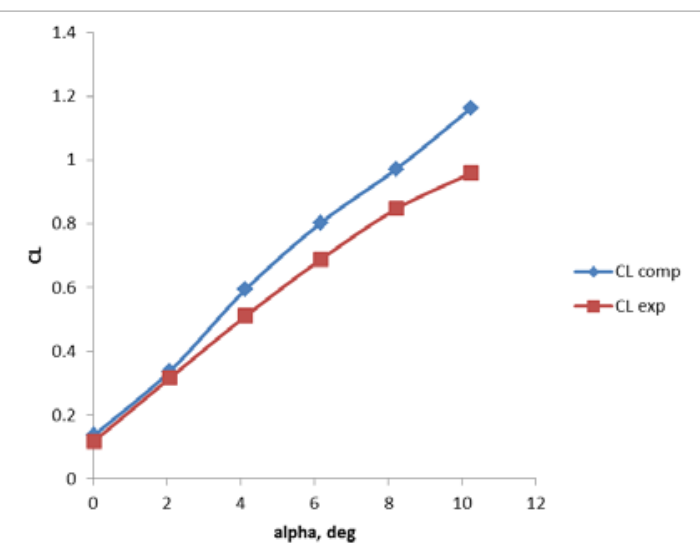

a) $\operatorname{Re}=1.0 \times 10^{6}, \mathrm{M}=0.1$

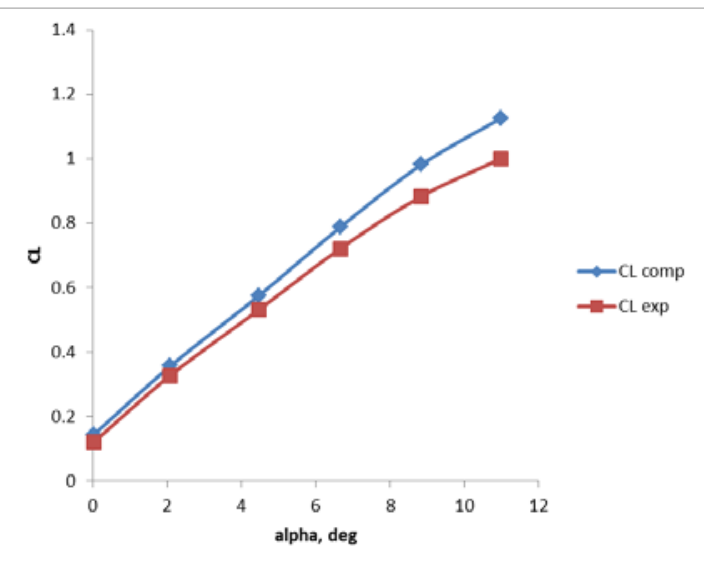

b) $R e=1.8 \times 10^{6}, M=0.18$

\section{Figure 11. Comparison of Computational and Experimental Lift Coefficient for Rime Ice Shape on NACA 23012 Airfoil Model.}

The closer agreement between computation and experiment at the higher Reynolds number and Mach number also indicate that accurate simulation of the viscous region plays a role in the overall computation. When the viscous influence on the results decreases as in the case shown here there becomes better agreement and the influence of the ice shape roughness details seems to have a lesser influence. These are, of course, just a single set of computations and further examination of the results as well as more comparisons to other experimental ice shape results will be required to verify such trends.

\section{Conclusion}

This study shows that it is possible to generate CFD grids representing highly complex 3D icing geometries and to perform viscous computational analysis on these CFD grids. Preliminary results show some correlation between computational results and experimental data but a general trend showed that computational pressure coefficient curves deviate somewhat from the experimental data. This discrepancy results in lift coefficient values that are larger than the values obtained from experiment. Further work needs to be done to determine what modifications to the analysis process will lead to higher correlation. Recommendations include running a parametric study on the refinement of the CFD grids, evaluate the turbulence models impact on the computations, develop a complete and robust method of calculating the 3D lift and drag forces from the computational surface pressures, and complete the angle of attack sweep for both the rime and glaze icing geometries to get a full comparison with the experimental data.

This study indicates that existing grid generation and CFD tools have the potential to provide research personnel with the ability to calculate the flow over a more accurate representation of an actual ice accretion surface. Such a capability has the potential to provide more information for determination of how ice shapes alter wing aerodynamics and how ice shape roughness impacts convective heat transfer rates during the accretion process. These improvements in turn could lead to more accurate ice accretion simulation tools and a more robust analysis of the impact of an icing encounter.

\section{Acknowledgments}

The authors would like to acknowledge the effort of Mr. Lloyd Utt for his assistance with preparation of the ice shape and airfoil surface data. Furthermore, the authors would like to acknowledge the work of Dr. Sam Lee and Dr. Andy Broeren in development of the ice shape scanning methodology which enabled the collection of the ice shape geometry data used in this study. 


\section{References}

[1] Lynch, F. T. and Khodadoust, A., "Effects of Ice Accretions on Aircraft Aerodynamics," Progress in Aerospace Sciences, Vol. 37, Issue 8, 2001, pp. 669-767

[2] Addy, H. E., Jr., “Ice Accretions and Icing Effects for Modern Airfoils,” NASA/TP-2000-210031, 2003.

[3] Broeren, A. P., Addy, H. E., Jr. Bragg, M. B., Busch, G. T., and Montreuil, E., “Aerodynamic Simulation of Ice Accretion on Airfoils,” NASA/TP-2011-216929, 2011.

[4] Papadakis, M., Yeong, H. W., Wong, S. C., Vargas, M., and Potapczuk, M., "Experimental Investigation of Ice Accretion Effects on a Swept Wing,” DOT/FAA/AR-05/39, 2005.

[5] Potapczuk, M. G., “Navier-Stokes Analysis of Airfoils with Leading Edge Ice Accretions,” NASA-CR-191008, 2003.

[6] Chi, X., Zhu, B., Shih, T. I.-P., Addy, H. E., and Choo, Y. K., “CFD Analysis of the Aerodynamics of a Business-Jet Airfoil with Leading-Edge Ice Accretion,” AIAA Paper 2004-0560, 2004.

[7] Kwon, O. J. and Sankar, L. N., "Numerical Investigation of Performance Degradation of Wings and Rotors Due to Icing," AIAA Paper 92-0412, 1992.

[8] Thompson, D., Mogili, P., Chalasani, S., Addy, H. E., and Choo, Y. K., “A Computational Icing Effects Study for a ThreeDimensional Wing,” AIAA Paper 2004-561, 2004.

[9] Reid, T., Baruzzi, G., Ozcer, I., Switchenko, D., and Habashi, W., "FENSAP-ICE Simulation of Icing on Wind Turbine Blades, Part 1: Performance Degradation,” AIAA Paper 2013-0750, 2013.

[10] Lee, S., Broeren, A. P., Addy, H. E., Jr., Sills, R., and Pifer, E. M., “Development of 3-D Ice Accretion Measurement Method,” NASA/TM-2012-217702, AIAA Paper-2012-2938, 2012

[11] Geomagic Studio, 3D Scanned Data Processing Software Package, Version 2014, Three D Systems, Rock Hill, SC, 2014.

[12] Pointwise, Mesh Generation Software for CFD, Version 17.1 Release 4, Pointwise, Inc., Fort Worth, TX, 2013.

[13] Chen, K.-H., Norris, A.T., Quealy, A., and Liu, N.-S., “Benchmark Test Cases for the National Combustion Code,” AIAA Paper 98-3855, July1998.

[14] Ajmani, K., and Chen, K.-H., “Unsteady Flow Computations for the NCC,” AIAA Paper 2001-0972, Jan. 2001.

[15] Liu, N.-S., “On the Comprehensive Modeling and Simulation of Combustion Systems,” AIAA Paper 2001-0805, 2001.

[16] Shuen, J.-S. Chen, K.-H. and Choi, Y., "A Coupled Implicit Method for Chemical Non-Equilibrium Flows at All Speeds," Comput. Phys., 106, pp. 306-318, 1993.

[17] Chen, K.- H. and Liu, N.-S., "Evaluation of A Non-Linear Turbulence Model Using Mixed Volume Unstructured Grids," AIAA 98-0233, 1998.

[18] Shih, T.-H., Liu, N.-S. and Chen, C.-L., “A Strategy for Very Large Eddy Simulation of Complex Turbulent Flows,” AIAA 2006-175, 44th AIAA Aerospace Sciences Meeting and Exhibit, 9-12 Jan. 2006, Reno, Nevada.

[19] Liu, N.-S. and Shih, T.-H., “Turbulent Modeling for Very Large-Eddy Simulation,” AIAA Journal, Vol. 44, No. 4, April 2006

[20] Liu, N.-S., Shih, T.-H., and Wey, T., “Comprehensive Combustion Modeling and Simulation: Recent Progress at NASA Glenn Research Center,” ISABE Paper 2007-1268, 2007.

[21] Shih, T.-H. and Liu, N.-S., "Modeling of Internal Reacting Flows and External Static Stall Flows Using RANS and PRNS,” Flow, Turbulence and Combustion, July 18, 2007.

[22] Tecplot 360, Flow Visualization Software Package, Version 2013 Release 1, Tecplot, Inc., Bellevue, WA, 2013.

[23] Broeren, A.P., Addy, H.E., Lee, S., and Monastero, M.C., "Validation of 3-D Ice Accretion Measurement Methodology for Experimental Aerodynamic Simulation,” AIAA 6 ${ }^{\text {th }}$ Atmospheric and Space Environments Conference, Atlanta, GA, June 16-20, 2014 (submitted for publication). 
[24] Caruso, S., "Development of an Unstructured Mesh/Navier-Stokes Method for Aerodynamics of Aircraft with Ice Accretions,” AIAA Paper 90-0758, Jan. 1990. 